\title{
POLICY IMPLICATION OF PRICE COLLUSION IN A DUOPOLY MARKET WITH DIFFERENTIATED PRODUCTS
}

\section{Doriani Lingga*, Damiana Simanjuntak}

\begin{abstract}
This paper uses a duopoly model with horizontally differentiated products to analyse how price collusion in the presence of a uniform tax affects market equilibrium. Moreover, this paper investigates the effect of price collusion on social welfare and the government's decision in setting the optimal tax. We show that in the presence of a uniform tax, instead of bringing social welfare down as is traditionally believed, price collusion affects government policy implication. We further show that firms still prefer colluding rather than competing, for which the government's policy decision becomes the key point. By allowing the optimal tax to be negative, we find that under Bertrand competition the government can impose a positive, zero or negative tax on firms depending on the level of the product differentiation. There is a tendency that the more heterogeneous the products, the more subsidies will be given. Under price collusion, the government always subsidises firms regardless of the degree of product differentiation. Finally, we show that when the products are sufficiently differentiated, the government will subsidise firms more under collusion than they will under Bertrand. In short, firms can use price collusion to induce the government to subsidise them.
\end{abstract}

Keywords: Bertrand competition, Collusion, Duopoly Market, Product Differentiation, Tax, Trade Policy, Social Welfare, Subsidy

JEL Classification: L30, H21, D60

\section{Introduction}

Collusion practices in industries have been proven to be socially undesirable. Collusion gives firms an incentive to gain more profit while eliminating fair competition from the market. Not only does it cause a loss in consumer surplus, it also damages the economy overall. As some firms acquire more market power, they eventually behave like a monopolist, which is definitely harmful to consumers. The replacement of fair competition, which is a motivation for efficiency and quality improvement, with collusion practices will worsen the economy. This is the reason why collusion practices are prohibited by antitrust laws in most countries in the world.

This phenomenon leads to a number of further questions regarding collusion. Is collusion definitely profitable to firms? ${ }^{1}$ How stable is collusion in the presence of industrial policies? ${ }^{2}$ Does collusion necessarily lower social welfare? The answers to

* Corresponding author, Department of Economics, Universitas Atma Jaya Yogyakarta, Indonesia (doriani_lingga@staff.uajy.ac.id).

We would like to thank the reviewers for their detailed comments and suggestions for the manuscript.

1 See Athey and Bagwell (2001) and Athey, Bagwell and Sanchirico (2004) showing how firms that are colluding can benefit.

2 See Harrington and Skrzypacz (2007, 2011); Chang (1991, 1992); Colombo (2010) and Hackner (1995) for references discussing collusion stability. 
these questions can yield more information about the presence of collusion in industries and its effect on social welfare and government trade policies.

Fershtman and Gandal (1994), by showing that collusion in the product market does not necessarily benefit firms, suggest that regulators still need to be diligent in the enforcement of antitrust laws. Meanwhile, Brod and Shivakumar (1999) point out that a production cartel can either benefit both firms and consumers or hurt both firms and consumers by considering the values of the spillover and product-differentiation parameters. In opposition to traditional wisdom that collusion damages social welfare, Deltas, Salvo and Vasconcelos (2012) by developing a model of geographically separated markets with differentiated goods, show that collusion (or merger to monopoly) is beneficial for society and can be beneficial for consumers. The finding of this paper supports the idea that the effects of price collusion on social welfare might have been exaggerated. For example, Fershtman and Pakes (2000) show that collusion can enhance social welfare by increasing both the number and quality of product offers.

Many studies have been conducted to analyse firms' incentive in practising collusion and its impact on social welfare. However, to the best of our knowledge, there has not been any that analyse the effect of collusion on a governments' trade policy decision. This paper fills this gap as we need to investigate how government should react to firms' collusion practices through its policies, in order to keep social welfare at the maximum. In this paper, we focus on price collusion (semi-collusion) as it is known to be the most common type of collusion in industries. This paper discusses price collusion in the presence of a uniform tax, which is allowed to be negative and further considers the welfare implication of price collusion itself. This will definitely affect the trade policy, namely tax and in this case, undertaken by the domestic government. While there has been much literature discussing how collusion can be welfare-enhancing, this paper emphasises the optimal tax charged by a government when firms practice such price collusion. We take horizontal product differentiation into account to point out certain conditions under which a government has the incentive to impose a tax or provide a subsidy.

There are four main contributions by this paper. First, we find that in the presence of a uniform tax, the equilibrium price and quantities, and therefore consumer surplus, when under price collusion can be identical to those under pure price competition (Bertrand competition). This is because social welfare is a matter of the transfer between the producer surplus and the government revenue/expenditure, which keeps the final social welfare unchanged. In brief, in the presence of tax, collusion practice only affects the government's policy implication instead of social welfare. Second, we show that despite identical equilibrium price and quantity, firms still prefer to collude rather than compete. Not only do they benefit from the competition missing from the market, but they also benefit from the policy undertaken by a government under a collusion regime. This result is confirmed by our third finding, which is that under the Bertrand regime a government can impose a positive, zero or negative tax on firms depending on the level of product differentiation. A government charges tax when the products are close to homogeneous and provide subsidies when the products are more heterogeneous. Whereas, under a collusion regime, a government always subsidises firms to prevent them from raising their prices. Thus, these firms can induce the government to provide subsidies by committing themselves to a price collusion agreement. Finally, we find that when products are sufficiently differentiated, the government will subsidise firms more 
under collusion than they would under Bertrand. This is because when the products are more differentiated, firms have more power to control the market which will definitely lead to a greater welfare loss. This loss will even be fostered if the firms collude. As compensation, the government will subsidise the firms to prevent them from exercising their market power. In short, product differentiation and the firms' decision over whether or not to collude greatly affect a government's policy decision.

The remainder of this paper is as follows: the second section previews the related literature, which supports this paper; the third section provides the basic model used in this paper; section four discusses the main results and section five concludes the paper.

\section{Literature Review}

There has been much literature discussing collusion practices in various industries. In regard to semi-collusion (price or quantity collusion) and full collusion (both price and quantity collusion), Steen and Sørgard (2009) conduct a survey of the literature on both types of collusion. In principle, full collusion generates (weakly) higher profits as it allows firms to mimic semi-collusion. Therefore, when price collusion and price-quantity collusion are approximately equally successful, one would not expect firms to make an additional agreement on output.

Van Den Berg and Bos (2016) analyse collusion among firms that simultaneously choose prices and quantities. They explore when and why firms would prefer to install a price-quota cartel rather than only a price-fixing agreement. They find that a pricefixing cartel optimally sets a price below the monopoly price in order to mitigate incentives to produce excessively. With this, a price-quota cartel is always more profitable as implementing an optimal allocation structure allows firms to sustain the monopoly price while avoiding wasteful production. Carree, et. al. (2010) provide many real-world examples of both price and price-quota cartels.

That collusion is preferable has been shown in much of the literature. Athey and Bagwell (2001) and Athey, Bagwell and Sanchirico (2004) show how colluding firms may benefit from an allocation structure when production costs are private information.

Meanwhile, some literature has shown that collusion can also be disadvantageous to firms. Fershtman and Gandal (1994) for example, by considering collusion in such activities as research and development (R\&D), show that collusion in the product market does not necessarily benefit firms. They further extend the analysis and find that semicollusion is disadvantageous to the firms and consumers do not necessarily benefit. Hence, they suggest that regulators still need to be diligent in the enforcement of antitrust laws. Brod and Shivakumar (1999) show that the values of the spillover and productdifferentiation parameters exist so that a production cartel can either benefit both firms and consumers or hurt both firms and consumers.

Harrington and Skrzypacz $(2007,2011)$ analyse the stability of collusion and show that a sophisticated output arrangement may be needed to sustain collusion when prices are not publicly observable. In relation to product differentiation, Chang $(1991,1992)$ analyses collusion using Hotelling (1929) with quadratic transportation costs. The result shows that the stability of collusion increases as the products are more differentiated. ${ }^{3}$

3 Ross (1992); Friedman and Thisse (1993). 
Colombo (2010) proposes three types of collusion (1) collusion on discriminatory prices; (2) collusion on a uniform price; (3) collusion not to discriminate. The result says that the sustainability of the first and the third collusive scheme does not depend on the product differentiation degree. The sustainability of the second collusive scheme instead depends negatively on the product differentiation degree.

Hackner (1995) considers the possibility that firms collude not only with respect to the price but also with respect to the location. When the market discount factor is high enough, firms collude to locate at $1 / 4$ and $3 / 4$. The lower the market discount factor, the more the firms collude on a higher product differentiation degree in order to stop the collusion from breaking down.

Some literature has also shown that collusion is not necessarily harmful to social welfare. Deltas, Salvo and Vasconcelos (2012) developed a model of geographically separated markets with differentiated goods in which collusion (or merger to monopoly), by restricting trade relative to duopolistic competition, is beneficial to society and can also be beneficial to consumers. Fershtman and Pakes (2000) show collusion can increase both the number and quality of product offerings although it also leads to higher prices. However, the positive effects through the variety and quality outweigh the higher price and therefore collusion can increase consumer welfare.

\section{The Basic Model}

The model in this paper is built on a duopoly model in which two firms compete in a domestic market. The demand function of each firm is specified as:

$$
q_{i}=a-b p_{i}+p_{j}, i, j=1,2, i \neq j,
$$

where $a$ is a constant, $q$ denotes quantity and $p$ denotes price. Subscript $i$ refers to variables corresponding to firm $i$ and subscript $j$ refers to those corresponding to firm $j$ with $i, j=1,2, i \neq j$. Coefficient $b$ refers to product differentiation while $b$ equals to one means that the products are homogeneous. For simplification without losing its generality, assume that firms incur no marginal production cost. Hence, the only cost that we consider is a uniform tax charged by the government on each firm. Furthermore, assume that the firms face a large market with a very high reservation price, namely $a$ is very high.

Each firm's objective function is as follows:

$$
\pi_{i}=\left(p_{i}-t\right)\left(a-b p_{i}+p_{j}\right) .
$$

Meanwhile, the government sets its level of tax policy to maximise social welfare, which consists of consumer surplus, producer surplus, and tax revenue. Specifically, the government's objective function is defined as:

$$
W=\frac{Q^{2}}{2}+\pi_{i}+\pi_{j}+t q_{i}+t q_{j},
$$

where $Q$ denotes quantity and is used in terms of consumer surplus. 
We consider a scenario in which anti-trust policies are not applicable in the country so that firms can choose to either compete under a non-cooperative Bertrand scheme or to commit themselves to price collusion.

Thus, the game involves a two-stage sub-game perfect equilibrium. In the first stage, the government sets its optimal tax and in the second stage the firms either compete under price fashion (Bertrand competition) or collude in setting the price. The game is solved by backward induction, starting from the final stage.

First, we investigate the firms' payoffs in the absence of tax to highlight the conditions under which price collusion is socially-undesirable as we traditionally presume. By omitting tax from the firms' objective function in equation (1), we can derive the first order condition and obtain each firm's reaction function as follows:

$$
p_{i}=\frac{1}{2 b}\left(a+p_{j}\right) .
$$

Denote $\gamma=(1 / 2 b)$ as degree of product differentiation. When $\gamma=1 / 2$ the products are homogeneous. Solving the reaction functions simultaneously yields the following Bertrand equilibrium:

$$
\begin{gathered}
p_{i}^{B}=p_{j}^{B}=\frac{a}{2 b-1}, \\
q_{i}^{B}=q_{j}^{B}=\frac{a b}{2 b-1}, \\
\pi_{i}^{B}=\pi_{i}^{B}=\frac{a^{2} b}{(2 b-1)^{2}},
\end{gathered}
$$

where superscript $B$ denotes variables in the Bertrand equilibrium.

Under such equilibrium, the level of social welfare, which consists of consumer surplus and the firms' total profit, is as follows:

$$
W^{B}=\frac{2 a^{2} b(b+1)}{(2 b-1)^{2}} .
$$

Now, consider the case where the firms commit to price collusion and both are loyal to the collusion agreement so that no firm has an incentive to deviate. The firms agree to set $p_{i}=p_{j}=p$ and each maximises:

$$
\pi=p(a+(1-b) p) .
$$

The resulting equilibrium is as follows:

$$
\begin{gathered}
p_{i}^{C}=p_{j}^{C}=\frac{a}{2(b-1)}, \\
q_{i}^{C}=q_{j}^{C}=\frac{a}{2},
\end{gathered}
$$




$$
\pi_{i}^{C}=\pi_{j}^{C}=\frac{a^{2}}{4(b-1)},
$$

where superscript $C$ denotes variables in collusive equilibrium.

Under collusive equilibrium, the social welfare is as follows:

$$
W^{C}=\frac{a^{2} b}{2(b-1)} \text {. }
$$

Comparing the level of the social welfare under Bertrand competition with that under price collusion, we find:

$$
W^{B}>W^{C} \quad b>5 / 4 \text { if } b>5 / 4 .
$$

This condition suggests that price collusion leads to welfare loss if the products are sufficiently heterogenous (i.e. $b>5 / 4$ ). Therefore, hereinafter we will assume that this condition holds to show that collusion is initially socially-undesirable.

The second order conditions for the profit maximisation problems under Bertrand competition are satisfied for any positive value of $b$, while those under price collusion are satisfied for $b>1$, which is definitely met by our constraint $b>5 / 4$.

Hereinafter, we will classify the regimes into pure price competition (Bertrand competition) and price collusion.

\section{Main Results}

\subsection{Pure Price Competition Regime}

Now consider the case in which both the firms incur a uniform tax charged by their domestic government. Take the two-stage game structure, which starts from the final stage when the firms compete under pure Bertrand fashion.

In this stage, each firm maximises the objective function as shown in equation (1). Solving the first order conditions for the firms' profit maximisation problems result in equilibrium under Bertrand competition, as follows:

$$
\begin{gathered}
p_{i}^{B t}=p_{j}^{B t}=\frac{a+b t}{2 b-1}, \\
q_{i}^{B t}=q_{j}^{B t}=\frac{b(a+(1-b) t)}{2 b-1}, \\
\pi_{i}^{B t}=\pi_{j}^{B t}=\frac{b(a+(1-b) t)^{2}}{(2 b-1)^{2}},
\end{gathered}
$$

with additional superscript $t$, which denotes equilibrium in the presence of tax. Note that the tax is positively correlated with the price so that an increase in the tax will raise the equilibrium price and henceforth straightforwardly reduce the market size as shown by the equilibrium quantities. We can see that under assumption $b>5 / 4$, the tax is negatively correlated with the equilibrium quantities. 
In the first stage, the domestic government maximises its domestic social welfare, which now consists of consumer surplus, the firms' total profit, and tax revenues. By substituting the values of the equilibrium prices, quantities, and profits under Bertrand competition we obtain in the equations (8) for the welfare maximisation problem in equation (2), that we can rewrite the government objective function as follows:

$$
W^{B t}=\frac{2 b^{2}(a+(1-b) t)^{2}}{(2 b-1)^{2}}+\frac{2 b t(a+(1-b) t)}{(2 b-1)}+\frac{2 b(a+(1-b) t)^{2}}{(2 b-1)^{2}} .
$$

Solving the first order condition to the objective function results in the optimal tariff to be set by the government as follows:

$$
t^{B t}=\frac{1}{2} \frac{a\left(2 b^{2}-2 b-1\right)}{b(2-b)(1-b)} .
$$

The second order condition for the welfare maximisation problem is fulfilled if $1<b<2$. Considering the constraints we have, we will further assume that the level of product differentiation is located between $5 / 4$ and 2 , so that the products are not extremely differentiated.

In addition, we allow the tax to be negative in order to show the possibility of subsidising instead of taxing the firms.

\subsection{Price Collusion Regime}

In the situation where the firms collude in setting the price, each firm agrees to set $p_{i}=p_{j}=p$ in the second stage and maximises:

$$
\pi=(p-t)(a+(1-b) p) .
$$

When each firm maximises the objective function, we obtain the collusive equilibrium in the presence of tax as follows:

$$
\begin{gathered}
p_{i}^{C t}=p_{j}^{C t}=p^{C t}=\frac{1}{2} \frac{(1-b) t-a}{1-b}, \\
q_{i}^{C t}=q_{j}^{C t}=-(a+(1-b) t), \\
\pi_{i}^{C t}=\pi_{j}^{C t}=\frac{(a+(-b) t)}{4} .
\end{gathered}
$$

We can see that under price collusion, the relations for tax with the equilibrium prices and quantities are consistent with those under pure price competition.

In the first stage, the domestic government maximises the social welfare. Substituting the provided values in equilibrium, the government's objective function can be rewritten as follows: 


$$
W^{C t}=\frac{1}{2}(a+(1-b) t)^{2}+t(a+(1-b) t)+\frac{1}{2} \frac{(a+(1-b) t)^{2}}{(b-1)} .
$$

By solving the first order condition to the welfare maximisation problem, we can obtain the optimal tariff for the domestic government as follows:

$$
t^{C t}=\frac{a}{b-2} .
$$

The same condition as that under Bertrand competition for the welfare maximisation problem to be satisfied is needed, namely $5 / 4<b<2$.

We can see clearly here that under price collusion, product differentiation moves in the opposite direction with tax. The more differentiated the product, the lower the tax charged by the domestic government will be.

\subsection{Price Competition versus Price Collusion}

Comparing the equilibrium under Bertrand competition and under collusion, we can imply that in the presence of tax, the argument that price collusion is socially undesirable is not necessarily true. This paper finds that price collusion is neither welfare-harming nor welfare-improving when the government intervene in the form of trade policies.

We can see this from the comparison between the two regimes' equilibrium prices and quantities after tax. By plugging the optimal taxes under each regime into the corresponding prices and quantities, we obtain:

$$
\begin{gathered}
p_{i}^{B t^{*}}=p_{j}^{B t^{*}}=p^{C t^{*}}=\frac{1}{2} \frac{(2 b-3) a}{(b-1)(b-2)}, \\
q_{i}^{B t^{*}}=q_{j}^{B t^{*}}=q_{i}^{C t^{*}}=q_{j}^{C t^{*}}=\frac{1}{2} \frac{a}{(2-b)}, \\
W^{B t^{*}}=W^{C t^{*}}=\frac{1}{2} \frac{a^{2}}{(1-b)(b-2)} .
\end{gathered}
$$

As we can see, in the presence of tax, the level of social welfare under Bertrand is identical to that under collusion. However, equations (10) and (14) show that there is a difference between the optimal taxes under the two regimes. Rewriting this result, we get:

Proposition 1. In the presence of a uniform tax, price collusion does not change the equilibrium prices, quantities, and social welfare from those under Bertrand competition. Instead, price collusion affects the government's policy implication.

This result is in contrast to what we traditionally know - that price collusion results in higher prices and lower quantities, which lead to lower consumer surplus and social welfare. The reason for this result is the trade policy adopted by the government. Knowing that firms engage in collusion practice and that these firms' profit-maximising price 
and quantities depend on the optimal tax, the government will anticipate the potential lower social welfare by adjusting the tax to its optimal welfare-maximising level. Thus, even if the firms commit to such price collusion, the equilibrium price and quantities remain the same as they are under Bertrand. In brief, the social welfare under the two regimes is merely a matter of a transfer between the firms and government leaving the consumer surplus unchanged. While the components of the social welfare under Bertrand differ from those under collusion, the overall welfare level itself remains the same.

These results emphasise the findings of Deltas, Salvo and Vasconcelos (2012) and Fershtman and Pakes (2000) who show that collusion is not necessarily harmful to social welfare, especially in the presence of tax as in our case.

Now, we plug in the optimal taxes under each regime into the corresponding profits of each firm, and find:

$$
\begin{gathered}
\pi_{i}^{B t^{*}}=\pi_{j}^{B t^{*}}=\frac{1}{4} \frac{a^{2}}{b(b-2)^{2}}, \\
\pi_{i}^{C t^{*}}=\pi_{j}^{C t^{*}}=\frac{1}{4} \frac{a^{2}}{(b-1)(b-2)^{2}} .
\end{gathered}
$$

With identical equilibrium prices and quantities, we surprisingly find that the firms' profits are still higher under price collusion than under Bertrand competition. This result can be rewritten as:

Proposition 2. Despite the identical equilibrium price and quantities, price collusion is still more preferable to the firms than when compared to Bertrand competition.

We already knew that under the Bertrand game, firms experience the most severe competition leading to lower profits in equilibrium and that price collusion can be used to ease competition. In addition to these advantages, in our scenario, the firms can benefit from the trade policy undertaken by the government.

We have seen how a government's decision is dependent on whether or not the firms commit themselves to a collusion agreement. In other words, the firms can affect the government's policy decision in their favour. After comparing the firms' profit under both regimes and finding that collusion still yields higher profit, it is reasonable to presume that the trade policies taken by a government under collusion benefit the firm more than those taken under Bertrand. An investigation of this argument will be discussed below as the main part of the discussion, which is comparing the optimal tax under Bertrand competition and under price collusion.

From equation (10), we find that under Bertrand competition, there are three possible types of policies depending on the degree of product differentiation: for $5 / 4<b<1.37$ the optimal tax is positive; for $b \approx 1.37$ the optimal tax is zero; for $1.37<b<2$, the optimal tax is negative.

Meanwhile, from equation (14) we find that under price collusion for any of the considered levels of product differentiation, the optimal tax is always negative. For this, we have: 
Proposition 3. Under Bertrand, the government can either tax or subsidise the firms, depending on the level of product differentiation. When the products are close to homogeneous, the government will tax them. When the products are moderately differentiated, the government will neither charge tax nor subsidise them. When the products are sufficiently heterogeneous, the government will subsidise them. Meanwhile, under collusion, the government will always subsidise firms regardless of the level of their product differentiation. In other words, collusion induces the government to subsidise the firms.

Under Bertrand, the more differentiated the product, the looser the tax set by the government. Eventually, when the level of product differentiation exceeds 1.37, the government starts to provide subsidies instead of charging a tax. The intuition behind this result is as follows.

First, the firms can use product differentiation to mitigate the magnitude of market competition. The more differentiated the product, the wider the firms' market coverage and less harsh competition occurs in the market. It implies that firms have more power to control the market. In this case, the government will subsidise firms to prevent them from raising their prices. In contrast, when the products are sufficiently homogeneous, the severe competition in the market is enough to prevent firms from increasing the market price of their products. In this case, instead of subsidising the firms, the government has the opportunity to impose a positive tax on them.

In the meantime, the government always subsidises firms when they collude regardless of the degree of the product differentiation. This is to compensate for any possible loss of consumer surplus due to the increasing price and decreasing quantities as a result of price collusion. To prevent this from taking place, the government decides to provide the firms with subsidies.

Interestingly, when the degree of product differentiation is relatively high, we find that the government will subsidise firms more under price collusion. Focusing on the case of $1.37<b<2$ in which the government will subsidise the firms under both regimes, we can see that the optimal tax under collusion is more negative than that under Bertrand. Rewriting this finding we get:

Proposition 4. When the products are sufficiently differentiated, the government will subsidise the firms more under collusion than they will under Bertand.

The firms are more attracted to collusion as the products are more differentiated. This is because by committing themselves to a collusion agreement, they can avoid market competition, enjoy the subsidy that is always provided under collusion, and hence generate higher profits. When the products are more differentiated, this advantage is even fostered through the market power that the firms have, which enables them to control in their favour the government's policy decision. The more that firms are attracted to price collusion, the more welfare loss could potentially occur and the more subsidies the government needs to provide to prevent this from taking place. 


\section{Conclusions}

Much of the literature has tried to show that collusion is not necessarily desirable for firms and that collusion is not necessarily harmful to social welfare. This paper discusses price collusion in the presence of uniform tax, analyses the effect of the price collusion on social welfare and studies how the price collusion affects a government's decision on setting its optimal tax. We find that in the presence of a uniform tax, the equilibrium price and quantities and therefore, the consumer surplus under price collusion can be identical to those under pure price competition (Bertrand competition). In other words, in the presence of tax, collusion practice only affects the government's policy implication instead of social welfare.

We also show that despite the identical equilibrium price and quantity, firms still prefer colluding rather than competing for the policy undertaken by the government that they can enjoy under collusion regime. It is confirmed that under the collusion regime, the government will always subsidise firms to prevent them from raising their price. Meanwhile, under the Bertrand regime, the government can impose a positive, zero or negative tax on firms depending on the level of product differentiation. The government charge tax when the products are close to homogeneous and provide subsidies when the products are more heterogeneous.

Finally, we find that when the products are sufficiently differentiated, the government will subsidise firms more under collusion than they will under Bertrand to prevent them from exercising their market power as they grow stronger with product differentiation and price collusion. Thus, product differentiation and the firms' decision of whether or not to collude altogether affect the government's policy decision.

\section{References}

Athey, S. and Bagwell, K. (2001). Optimal Collusion with Private Information. RAND Journal of Economics, 32(3), pp. 428-465, https://doi.org/10.2307/2696363

Athey, S., Bagwell, K. and Sanchirico, C. (2004). Collusion and Price Rigidity. Review of Economic Studies, 71(2), pp. 317-349, https://doi.org/10.1111/0034-6527.00286

Brod, A. and Shivakumar, R. (1999). Advantageous Semicollusion. The Journal of Industrial Economics, 47(2), pp. 221-230, https://doi.org/10.1111/1467-6451.00098

Carree, M., Günster, A. and Schinkel, M. P. (2010). European Antitrust Policy 1957-2004: An Analysis of Commission Decisions. Review of Industrial Organization, 36(2), pp. 97-131, https://doi.org/10.1007/s11151-010-9237-9

Chang, M. H. (1991). The Effects of Product Differentiation on Collusive Pricing. International Journal of Industrial Organization, 9(3), pp. 453-469, https://doi.org/10.1016/0167-7187(91)90023-E

Chang, M. H. (1992). Intertemporal Product Choice and Its Effects on Collusive Firm Behavior. International Economic Review, 33(4), pp. 773-793, https://doi.org/10.2307/2527142

Colombo, S. (2010). Product Differentiation, Price Discrimination and Collusion. Research in Economics, 64(1), pp. 18-27, https://doi.org/10.1016/j.rie.2009.10.003

Deltas, G., Salvo, A. and Vasconcelos, H. (2012). Consumer-surplus-enhancing Collusion and Trade. The RAND Journal of Economics, 43(2), pp. 315-328,

https://doi.org/10.1111/j.1756-2171.2012.00167.x 
Fershtman, C. and Gandal, N. (1994). Disadvantageous Semicollusion. International Journal of Industrial Organization, 12(2), pp. 141-154, https://doi.org/10.1016/0167-7187(94)90010-8

Fershtman, C. and Pakes, A. (2000). A Dynamic Oligopoly with Collusion and Price Wars. RAND Journal of Economics, 31, pp. 207-236, https://doi.org/10.2307/2601038

Hackner, J. (1994). Collusive Pricing in Markets for Vertically Differentiated Products. International Journal of Industrial Organization, 12(2), pp. 155-177, https://doi.org/10.1016/0167-7187(94)90011-6

Hackner, J. (1995). Endogenous Product Design in an Infinitely Repeated Game. International Journal of Industrial Organization, 13(2), pp. 277-299, https://doi.org/10.1016/0167-7187(94)00451-7

Harrington, J. E. and Skrzypacz, A. (2007). Collusion under Monitoring of Sales. RAND Journal of Economics, 38(2), pp. 314-331, https://doi.org/10.1111/j.1756-2171.2007.tb00070.x

Harrington, J. E. and Skrzypacz, A. (2011). Private Monitoring and Communication in Cartels: Explaining Recent Collusive Practices. American Economic Review, 101(6), pp. 2425-2449, https://doi.org/10.1257/aer.101.6.2425

Hotelling, H. (1929). Stability in Competition. The Economic Journal, 39(153), pp. 41-57, https://doi.org/10.2307/2224214

Liu, Q. and Serfes, K. (2007). Market Segmentation and Collusive Behavior. International Journal of Industrial Organization, 25(2), pp. 353-378, https://doi.org/10.1016/j.ijindorg.2006.05.004

Ross, T.W. (1992). Cartel Stability and Product Differentiation. International Journal of Industrial Organization, 10(1), pp. 1-13, https://doi.org/10.1016/0167-7187(92)90043-X

Steen, F. and Sørgard, L. (2009). Semicollusion. Foundations and Trends in Microeconomics, 5(3), pp. 153-228, https://doi.org/10.1561/0700000034

Van Den Berg, A. and Bos, I. (2017). Collusion in a Price-Quantity Oligopoly. International Journal of Industrial Organization, 50, pp. 159-185, https://doi.org/10.1016/j.ijindorg.2016.12.001 